\begin{tabular}{c|l|l|l}
$\begin{array}{c}\text { Case Reports in } \\
\text { Oncology }\end{array}$ & $\begin{array}{l}\text { Case Rep Oncol 2010;3:423-427 } \\
\text { DOI: 10.1159/000322675 }\end{array}$ & $\begin{array}{l}\text { Published online: } \\
\text { November 22, 2010 }\end{array}$ & $\begin{array}{l}\text { O 2010 S. Karger AG, Basel } \\
\text { ISSN 1662-6575 } \\
\text { www.karger.com/cro }\end{array}$ \\
\hline
\end{tabular}

This is an Open Access article licensed under the terms of the Creative Commons AttributionNonCommercial-NoDerivs 3.0 License (www.karger.com/OA-license), applicable to the online version of the article only. Distribution for non-commercial purposes only.

\title{
Oxaliplatin-Related Ocular Toxicity
}

\author{
Marina Mesquida ${ }^{a}$ Bernardo Sanchez-Dalmau ${ }^{a, c}$ \\ Santiago Ortiz-Perez ${ }^{a} \quad$ Laura Pelegrín $^{a}$ \\ Juan José Molina-Fernandez ${ }^{\mathrm{a}}$ Marc Figueras-Roca ${ }^{\mathrm{a}}$ \\ Ricardo Casaroli-Marano ${ }^{\mathrm{a}, \mathrm{c}}$ Alfredo Adán ${ }^{\mathrm{a}-\mathrm{c}}$ \\ aOphthalmology Department, Hospital Clínic de Barcelona, \\ bInstituto de Microcirugía Ocular, and 'Surgical Department, Facultat de \\ Medicina, Universitat de Barcelona, Barcelona, Spain
}

\section{Key Words}

Chemotherapeutic drugs · Electrooculogram · FOLFOX · Optic nerve · Oxaliplatin · Retina · Retinal pigment epithelium

\begin{abstract}
We report the case of a 52-year-old woman with advanced colorectal cancer who was treated with oxaliplatin on a FOLFOX schedule. After 3 cycles of chemotherapy, she started to complain of visual loss, altered color vision and neurological symptoms. Due to the suspicion of ocular and neurological toxicity, antineoplastic treatment was stopped. Her visual field showed a concentric bilateral scotoma and the electrooculogram test revealed severe impairment of the retinal pigment epithelium. Visual acuity, color vision and visual field recovered completely 8 months later, although electrooculogram remained abnormal. Ocular toxicity has been reported as an infrequent adverse event of oxaliplatin. Findings in this case indicate toxicity of this chemotherapeutic agent on the retinal pigment epithelium, which has not been reported before. This damage could be permanent, and it thus differs from previously described oxaliplatin-induced ocular toxicities, which are usually transient and reversible. With increasing use of oxaliplatin as first-line treatment in advanced colorectal cancer, we have to be aware of this possible toxicity.
\end{abstract}

\section{Introduction}

Oxaliplatin is a third-generation platinum-based chemotherapy used in the first-line treatment of advanced colorectal cancer [1]. Main side effects associated to this drug are neurotoxicity, mild hematological toxicity (neutropenia, thrombocytopenia, and anemia) and gastrointestinal symptoms (nausea, vomiting and/or diarrhea). Oxaliplatin-induced neurotoxicity is a prominent side effect and has emerged as the major dose-limiting 
toxicity $[2,3]$. Two different types of neurotoxicity have been described [3-5]. The first type, acute neurotoxicity, develops immediately following infusion and is characterized by transient paresthesia and muscular spasm, often induced or aggravated by exposure to cold. The second type, chronic neurotoxicity, produces sensory dysfunction with distal dysesthesias and paresthesias that can lead to sensory ataxia and functional impairment of fine sensorimotor coordination. It is a dose-dependent and cumulative toxicity. Symptoms are generally reversible, although they sometimes may persist in the long term in spite of treatment discontinuation [3-5].

Ocular toxicity is an uncommon but possible side effect of oxaliplatin. Oxaliplatin has been documented to produce a variety of ocular changes, most of them being transient and reversible [6]. Reported adverse effects vary from seemingly mild changes, such as dry eyes, tearing, conjunctivitis and abnormal lacrimation, to more severe and sometimes permanent changes, such as retinal damage or visual field cuts [6]. Patients receiving oxaliplatin therapy may complain of blurred vision, visual loss, tunnel vision, altered color vision and other symptoms [7]. The mechanism of this toxicity remains unknown.

\section{Case Report}

A 52-year-old female patient experienced visual changes while receiving oxaliplatin. After 3 cycles of chemotherapy on a FOLFOX-4 schedule (a combination of oxaliplatin, leucovorin and 5-fluorouracil), she complained of blurred vision and altered color vision as well as neurological symptoms, such as paresthesia of the extremities and laryngeal dysesthesia. Oncologists categorized these symptoms as grade- 3 neurotoxicity and the patient was referred to our department for evaluation of ophthalmic symptoms.

On examination, the best corrected visual acuity (BCVA) was 15/25 in the right eye (RE) and 20/30 in the left eye (LE). The Ishihara color test was 11/21 in the RE and 19/21 in the LE. Fundus examination did not demonstrate any alteration in the retina or the optic head (fig. 1). Visual field examination showed a severe bilateral concentric scotoma with mild central defect (fig. 2), and the electrooculogram test revealed a deeply diminished response in both eyes, with an Arden Index $<95 \%$. Macular and optic nerve optical coherence tomography (OCT) as well as electroretinogram and evoked potentials had normal results ( $\underline{\text { fig. }}$. 3). Antineoplastic treatment was stopped due to the occurrence of neurological and ocular toxicity. Visual disturbances improved progressively 3 weeks after chemotherapy discontinuation until complete resolution. Eight months after the onset of ocular symptoms, BCVA was 20/20 in both eyes, visual field showed only mild residual defects (fig. 3 ), and the Ishihara color test was $21 / 21$ in both eyes, although electrooculogram remained abnormal.

\section{Discussion}

Ocular side effects related to chemotherapeutic drugs, although uncommon, have been documented with a wide variety of symptoms $[8,9]$. In spite of their low frequency, ocular toxicities associated to this group of drugs are important because they can potentially lead to visual loss and permanent damage of ocular structures [10]. An association between chemotherapeutic drugs and visual disturbances is difficult to establish because of their low incidence and the coexistence of multiple and simultaneous factors which can lead to changes in ocular function and structure [10]. Therefore, patients should be questioned about the presence of visual impairments, and healthcare professionals must be alert to this possibility to notice any change in visual function. In case of appearance of visual changes, a complete ophthalmologic examination must be performed [10], including 


\begin{tabular}{c|l|l|l}
$\begin{array}{c}\text { Case Reports in } \\
\text { Oncology }\end{array}$ & $\begin{array}{l}\text { Case Rep Oncol 2010;3:423-427 } \\
\text { DOI: 10.1159/000322675 }\end{array}$ & $\begin{array}{l}\text { Published online: } \\
\text { November 22, 2010 }\end{array}$ & $\begin{array}{l}\text { O 2010 S. Karger AG, Basel } \\
\text { ISSN 1662-6575 } \\
\text { www.karger.com/cro }\end{array}$ \\
\hline
\end{tabular}

complementary tests, e.g. computerized perimetry, OCT and electrophysiological tests, which can help to unmask ocular toxicity in these patients.

Oxaliplatin is a platinum-based anticancer drug used in combination with infusional 5-fluorouracil and leucovorin in the first-line treatment of patients with metastatic colorectal cancer [1]. Ocular toxicity related to oxaliplatin is uncommon but possible. It has been documented to produce a variety of ocular changes, most of them transient and reversible, but sometimes permanent changes occur, such as retinal and optic nerve damage.

\section{Conclusion}

Our findings suggest that oxaliplatin can lead to damage of the retinal pigment epithelium and the optic nerve, resulting in visual loss and altered color vision, with permanent lesions in the electrooculogram and transient tunnel vision with concentric scotoma in the computerized perimetry, resolving after discontinuation of oxaliplatin therapy. Although several ocular changes have been reported related to oxaliplatin [6], we are unaware of previous reports of toxicity to the retinal pigment epithelium as a complication of oxaliplatin treatment.

In conclusion, healthcare clinicians should be alert to this potential toxicity when administering antineoplastic agents, especially platinum compounds like oxaliplatin, in order to detect and prevent visual loss and damage to ocular structures.

\section{Acknowledgments}

We would like to thank the Oncology Unit of the Hospital Clinic de Barcelona for referring the patient to us and providing us with their oncologic knowledge, which allowed us to interpret the clinical findings.

\section{Disclosure Statement}

The authors do not have any financial conflict of interest. 


\begin{tabular}{c|l|l|l}
$\begin{array}{c}\text { Case Reports in } \\
\text { Olloloyy }\end{array}$ & $\begin{array}{l}\text { Case Rep Oncol 2010;3:423-427 } \\
\text { DOI: 10.1159/000322675 }\end{array}$ & $\begin{array}{l}\text { Published online: } \\
\text { November 22, 2010 }\end{array}$ & $\begin{array}{l}\text { ISSN 1662-6575 } \\
\text { www.karger.com/cro }\end{array}$ \\
\hline
\end{tabular}

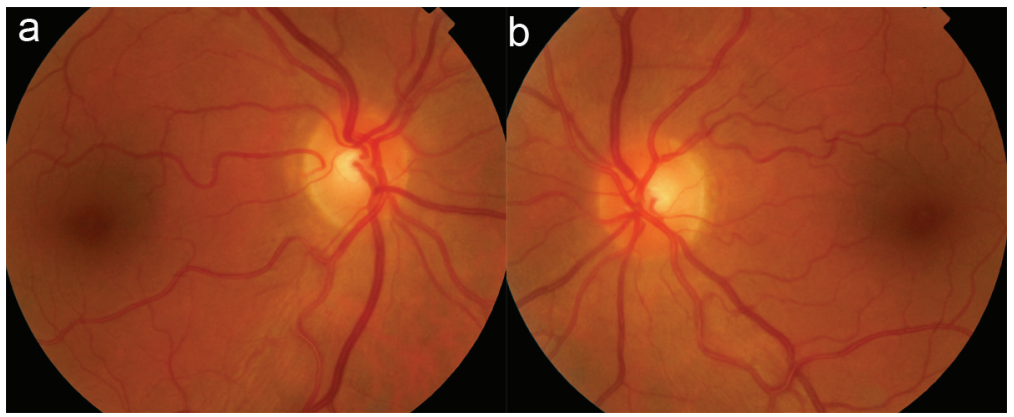

Fig. 1. Retinography. Fundus examination did not show any alteration in the macular area or optic disc in both RE (a) and LE (b).
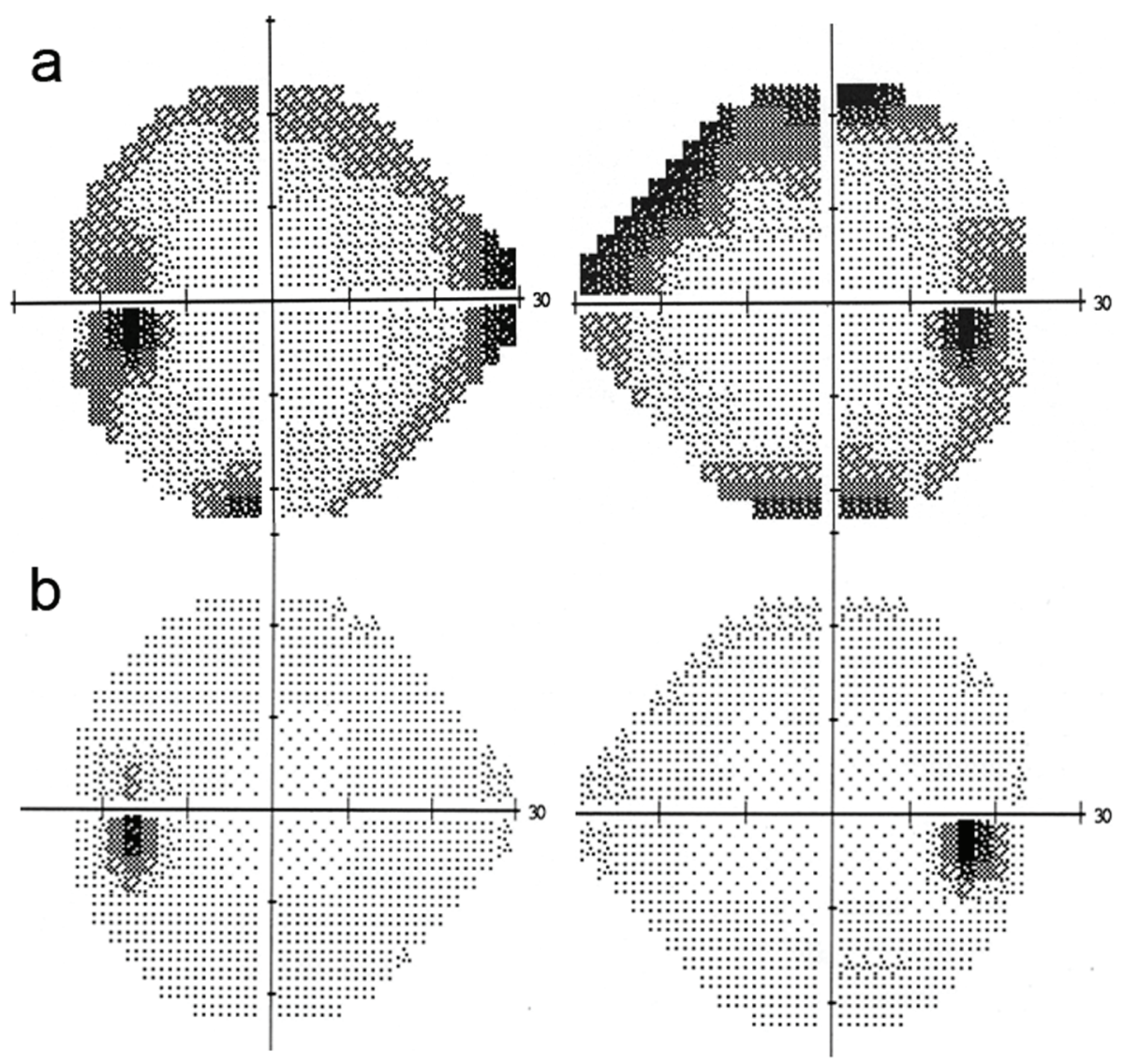

Fig. 2. Computerized perimetry. a First visual field performed after 1 month without oxaliplatin chemotherapy showed a concentric defect with deeply diminished light sensitivity. BCVA was 20/30 in the RE and 15/25 in the LE. b After 8 months without oxaliplatin, the visual field shows practically complete recovery of light sensitivity in both eyes, with only mild residual defects remaining. BCVA was $20 / 20$ in both eyes. 

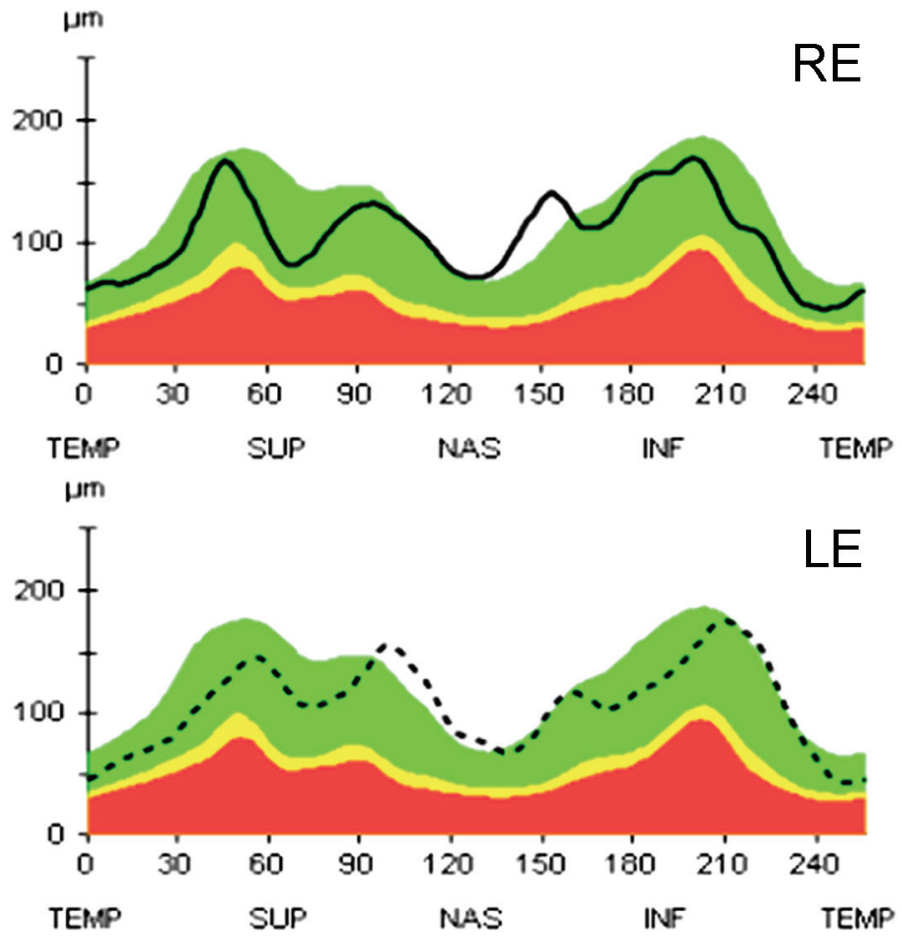

Fig. 3. Optical coherence tomography. OCT of the optic nerve head reveals a normal retinal nerve fiber layer of both optic discs (RE and LE).

\section{References}

1 De Gramont A, Figer A, Seymour M, Homerin M, Hmissi A, Cassidy J, Boni C, Cortes-Funes H, Cervantes A, Freyer G, Papamichael D, Le Bail N, Louvet C, Hendler D, de Braud F, Wilson C, Morvan F, Bonetti A: Leucovorin and fluorouracil with or without oxaliplatin as first-line treatment in advanced colorectal cancer. J Clin Oncol 2000;18:2938-2947.

$\checkmark 2$ Cassidy J, Misset JL: Oxaliplatin-related side effects: characteristics and management. Semin Oncol 2002;29:11-20.

- 3 Park SB, Lin CS, Krishnan AV, Goldstein D, Friedlander ML, Kiernan MC: Oxaliplatin-induced neurotoxicity: changes in axonal excitability precede development of neuropathy. Brain 2009;132:2712-2723.

- O'Dea D, Handy C, Wexler A: Ocular changes with oxaliplatin. Clin J Oncol Nurs 2006;10:227-229.

5 Leonard G, Wright M, Quinn M: Survey of oxaliplatin-associated neurotoxicity using an interview-based questionnaire in patients with metastatic colorectal cancer. BMC Cancer 2005;5:116-125.

6 Simpson D, Dunn C, Curran M, Goa KL: Oxaliplatin, a review of its use in combination therapy for advanced metastatic colorectal cancer. Drugs 2003;63:2127-2156.

7 Imperia PS, Lazarus HM, Lass JH: Ocular complications of systemic cancer chemotherapy. Surv Ophthalmol 1989;34:209-230.

-8 Tang RA, Kellaway J, Young SE: Ophthalmic manifestations of systemic cancer. Oncology 1991;5:59-66.

9 Grothey A: Clinical management of oxaliplatin-associated neurotoxicity. Clin Colorectal Cancer 2005;5:38-46.

10 Grothey A: Oxaliplatin-safety profile: neurotoxicity. Semin Oncol 2003;30:5-13. 